ARTICLE

DOI: $10.1038 / \mathrm{s} 41467-018-03671-5$

\title{
Valence and spin states of iron are invisible in Earth's lower mantle
}

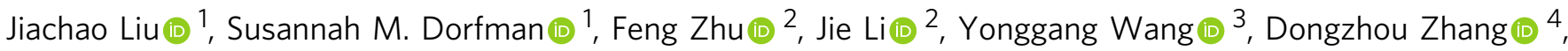 \\ Yuming Xiao ${ }^{5}$, Wenli $\mathrm{Bi}^{6,7} \&$ E. Ercan Alp 6
}

Heterogeneity in Earth's mantle is a record of chemical and dynamic processes over Earth's history. The geophysical signatures of heterogeneity can only be interpreted with quantitative constraints on effects of major elements such as iron on physical properties including density, compressibility, and electrical conductivity. However, deconvolution of the effects of multiple valence and spin states of iron in bridgmanite (Bdg), the most abundant mineral in the lower mantle, has been challenging. Here we show through a study of a ferric-iron-only $\left(\mathrm{Mg}_{0.46} \mathrm{Fe}^{3}\right.$ $\left.{ }_{0.53}\right)\left(\mathrm{Si}_{0.49} \mathrm{Fe}^{3+}{ }_{0.51}\right) \mathrm{O}_{3} \mathrm{Bdg}$ that $\mathrm{Fe}^{3+}$ in the octahedral site undergoes a spin transition between 43 and $53 \mathrm{GPa}$ at $300 \mathrm{~K}$. The resolved effects of the spin transition on density, bulk sound velocity, and electrical conductivity are smaller than previous estimations, consistent with the smooth depth profiles from geophysical observations. For likely mantle compositions, the valence state of iron has minor effects on density and sound velocities relative to major cation composition.

\footnotetext{
${ }^{1}$ Department of Earth and Environmental Sciences, Michigan State University, East Lansing, MI 48824, USA. ${ }^{2}$ Department of Earth and Environmental Sciences, University of Michigan, Ann Arbor, MI 48109, USA. ${ }^{3}$ Center for High Pressure Science and Technology Advanced Research (HPSTAR), Beijing 100094, China. ${ }^{4}$ School of Ocean and Earth Science and Technology, Hawai'i Institute of Geophysics and Planetology, University of Hawaii at Manoa, Honolulu, HI 966822, USA. ${ }^{5}$ HPCAT, Geophysical Laboratory, Carnegie Institution of Washington, Argonne, IL 60439, USA. ${ }^{6}$ Advanced Photon Source, Argonne National Laboratory, Argonne, IL 60439, USA. ${ }^{7}$ Department of Geology, University of Illinois at Urbana-Champaign, Urbana, IL 61801, USA. Correspondence and requests for materials should be addressed to J.L. (email: jiacliu09@gmail.com) or to S.M.D. (email: dorfman3@msu.edu)
} 
$\mathrm{V}$ ariation of redox conditions in the mantle, both laterally and vertically, is a natural consequence of differentiation and mixing processes in the mantle over its history. Early Earth processes segregated reduced iron through the mantle to the metallic core and generated the habitable oxygen-rich surface. Modern convection carries oxidized and iron-rich subducted basalt to the lower mantle ${ }^{1}$, while plumes ascending from the lowermost mantle may be reduced ${ }^{2}$. Regional and depth variation of oxygen fugacity, $\mathrm{fO}_{2}$, in the mantle has been confirmed by compositional variability in basalts ${ }^{3}$ and mantle mineral inclusions in diamonds ${ }^{4,5}$.

Constraints on mantle redox heterogeneity are also important to interpreting remote observations of heterogeneous geophysical properties. Geophysical methods, such as seismic ${ }^{6-8}$, geoid ${ }^{9,10}$ and geomagnetic ${ }^{11,12}$ observations, have been applied globally to image thermochemical variability in the mantle. Besides subducted slabs, observed heterogeneity in seismic tomography includes large-scale features at the base of the lower mantle, which may be thermochemical piles. Two large low shear velocity provinces (LLSVPs) located nearly antipodally beneath the Pacific Ocean and Africa are characterized by lower-than-average shear $\left(V_{\mathrm{S}}\right)$ and compressional $\left(V_{\mathrm{p}}\right)$ wave velocities ${ }^{6,7}$, and possibly elevated bulk sound velocity $\left(V_{\mathrm{B}}\right)^{13}$ and density ${ }^{14,15}$. Evidence for chemical differences between these regions and the surrounding mantle includes sharp margins and anti-correlated anomalies between $V_{\mathrm{B}}$ and $V_{\mathrm{S}}$ in LLSVPs ${ }^{16}$. Although the identity and origin of these regions is still unknown, the likely high density of LLSVPs may be explained by enrichment in $\mathrm{Fe}^{17}$.

Redox heterogeneity is likely to be expressed by differences in $\mathrm{Fe}^{3+} / \Sigma \mathrm{Fe}$ in mantle minerals, but the effects of $\mathrm{Fe}^{3+} / \Sigma \mathrm{Fe}$ ratios on observable mantle properties and the corresponding influence on the geophysical and geochemical evolution of the Earth are not well understood. The lower mantle's dominant mineral ( $\mathrm{Mg}, \mathrm{Fe}$, $\mathrm{Al})(\mathrm{Fe}, \mathrm{Al}, \mathrm{Si}) \mathrm{O}_{3}$ bridgmanite (Bdg) accommodates both $\mathrm{Fe}^{2+}$ and $\mathrm{Fe}^{3+}$, with each species corresponding to potentially different effects on thermoelastic and transport properties ${ }^{18}$. The effects of $\mathrm{Fe}^{2+}$ and $\mathrm{Fe}^{3+}$ on incompressibility of $\mathrm{Bdg}$ are thought to be opposite ${ }^{19}$. The density contrast between $\mathrm{Fe}^{2+}$ - and $\mathrm{Fe}^{3+}$-dominant Bdg may result in separation of oxidized and reduced materials through mantle convection and leave imprints in geochemical and isotopic composition ${ }^{20}$. However, in many experimental studies on $\mathrm{Bdg}, \mathrm{Fe}^{3+} / \Sigma \mathrm{Fe}$ was not characterized. Moreover, the compositions of Bdg synthesized in laser heated diamond anvil cells (DACs) are, in general, not well-controlled due to unknown oxygen fugacity, inhomogeneity in micron-scale starting materials, and cation migration by Soret diffusion at high temperatures. Such uncertainties in chemistry hamper the investigation of the effects of $\mathrm{Fe}^{3+} / \Sigma \mathrm{Fe}$ on thermoelastic and electrical properties of Bdg.

Pressure-driven electronic spin-pairing transitions of iron could further distinguish oxidized from reduced Bdg. Highpressure experimental and theoretical studies have concluded that $\mathrm{Fe}^{3+}$ in the octahedral B-site of Bdg undergoes a high spin (HS) to low spin (LS) transition under lower mantle pressure-temperature $(P-T)$ conditions (e.g., refs. $\left.{ }^{21-26}\right)$. Although this spin transition is generally accepted, discrepancies remain in the pressure conditions of the transition reported in previous experimental studies, e.g., $18-25 \mathrm{GPa}^{24}$ vs. $50-70$ $\mathrm{GPa}^{21,22}$. These differences could originate from experimental protocol (e.g., ref. ${ }^{24}$ ) or composition-dependence of the spin transition (e.g., ref. ${ }^{26}$ ). In contrast to $\mathrm{Fe}^{3+}$ in the B-site, both $\mathrm{Fe}^{2+}$ and $\mathrm{Fe}^{3+}$ accommodated in the larger pseudo-dodecahedral Asite will not experience a spin transition under the mantle $P-T$ conditions (reviewed by ref. ${ }^{27}$ ), though some authors have suggested a transition of $\mathrm{Fe}^{2+}$ to an intermediate-spin state ${ }^{28,29}$, which has not been supported by theoretical calculations ${ }^{23,30}$. As a result, the spin transition is only likely to influence the thermoelastic and transport properties of $\mathrm{Bdg}$ with $\mathrm{Fe}^{3+}$ in the $\mathrm{B}$-site. Geophysical relevance of spin transitions in mantle minerals has been debated, as throughout most of the lower mantle, properties such as seismic wave speeds ${ }^{31}$ and electrical conductivity ${ }^{11,12}$ do not exhibit discontinuous changes with depth. On the other hand, the spin transition in ferropericlase ( $\mathrm{Fp}$ ) has been suggested to generate a viscosity minimum around $1600 \mathrm{~km}$ with important implications for mantle dynamics and interpretation of the geoid $^{32,33}$. If a spin transition in Bdg occurs at similar depths, it may have similar effects on viscosity. Constraints on the effects of the spin transition in Bdg on density, elasticity, viscosity, and thermal and electrical conductivities are key to resolving the geophysical behavior of oxidized regions of the lower mantle.

To disentangle valence and spin effects on the elastic and electrical behavior of Bdg under high pressures, we conducted Xray diffraction (XRD), X-ray emission spectroscopy (XES), timedomain synchrotron Mössbauer spectroscopy (SMS) and electrical conductivity measurements on $\left(\mathrm{Mg}_{0.46} \mathrm{Fe}^{3+}{ }_{0.53}\right)\left(\mathrm{Si}_{0.49} \mathrm{Fe}^{3}\right.$ $\left.{ }_{0.51}\right) \mathrm{O}_{3} \mathrm{Bdg}$ at lower mantle pressures up to $85 \mathrm{GPa}$ and $300 \mathrm{~K}$. These complementary results from our well-characterized Bdg sample demonstrate that the spin transition of $\mathrm{Fe}^{3+}$ in the Bdg B-site happens between 43 and $53 \mathrm{GPa}$ at $300 \mathrm{~K}$. With improved constraints on the effects of $\mathrm{Fe}^{3+}$ on the equation of state (EoS) and electrical conductivity of Bdg, we conclude that neither oxidation state nor spin state of Fe in Bdg would cause significant anomalies in geophysical properties of mantle heterogeneities.

\section{Results}

Synthesis and characterization of Bdg. A unique opportunity to unambiguously determine the behavior of oxidized, Al-free Bdg at lower mantle conditions was presented by our discovery of a complete, reversible phase transition at $22-26 \mathrm{GPa}$ and $300 \mathrm{~K}$ from $\mathrm{Fe}^{3+}$-bearing akimotoite to $\mathrm{Bdg}$. A representative fullprofile Le Bail refinement of Bdg at $44.8 \mathrm{GPa}$ is shown in Fig. 1, where all peaks were identified as orthorhombic $\mathrm{GdFeO}_{3}$-type $\mathrm{Bdg}, \mathrm{Au}$, or Ne. Purely ferric Bdg with $\mathrm{Fe}^{3+}$ evenly distributed between the A- and B-sites is ideal for studying the spin transition of $\mathrm{Fe}^{3+}$ because variations of its density, spin moment, hyperfine parameters, and electrical conductivity with respect to pressure are not influenced by $\mathrm{Fe}^{2+}$ or cation exchange. The composition

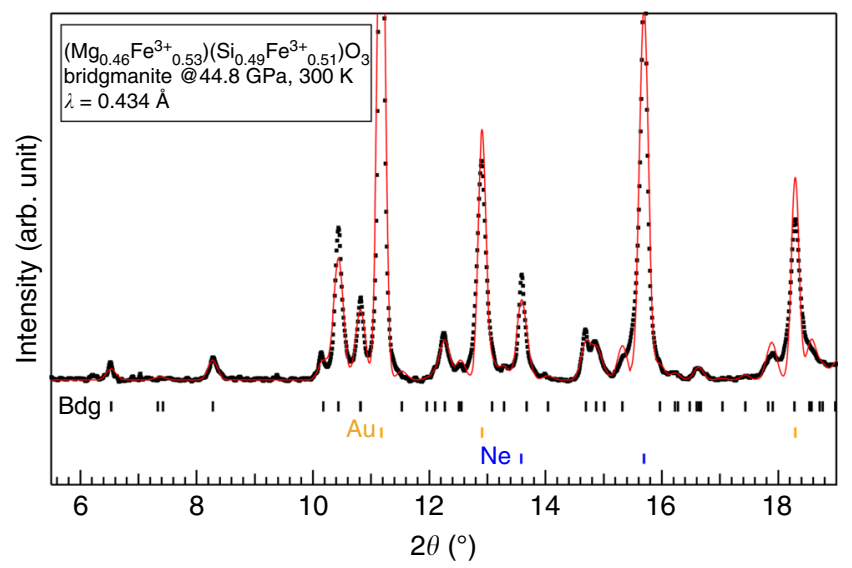

Fig. 1 Full-profile Le Bail refinement confirms transformation of akimotoite to bridgmanite (Bdg) structure. Measured XRD data for $\left(\mathrm{Mg}_{0.46} \mathrm{Fe}^{3+}{ }_{0.53}\right)$ ( $\left.\mathrm{Si}_{0.49} \mathrm{Fe}^{3+}{ }_{0.51}\right)_{3}$ composition at $44.8 \mathrm{GPa}$ and $300 \mathrm{~K}$ (black dots) are consistent with orthorhombic $\mathrm{GdFeO}_{3}$-type Bdg (black ticks below). Le Bail fit (red curve) also includes expected peak positions for Au calibrant (yellow ticks) and Ne medium (blue ticks) 
of the akimotoite starting material was determined by electron microprobe analysis to be $\mathrm{Mg}_{0.46} \mathrm{Fe}_{1.04} \mathrm{Si}_{0.49} \mathrm{O}_{3}$ (Supplementary Fig. 1). In Bdg synthesized from this composition at 26-71 GPa, SMS (Supplementary Fig. 2) are composed of two Fe sites of equal weight with quadrupole splitting (QS) values $<1.5 \mathrm{~mm} \mathrm{~s}^{-1}$ and similar center shift (CS) values $\left(\Delta \mathrm{CS}<0.3 \mathrm{~mm} \mathrm{~s}^{-1}\right.$, Supplementary Table 1). These values are consistent with the hyperfine parameters for $\mathrm{Fe}^{3+}$ of $\mathrm{Bdg}$ derived from synchrotron-based energy-domain Mössbauer spectroscopy ${ }^{34,35}$ (Supplementary Fig. 3). This confirms that all iron in the Bdg sample is $\mathrm{Fe}^{3+}$ and stoichiometry suggests that $\mathrm{Fe}^{3+}$ is distributed almost evenly between the A- and B-sites, yielding a Bdg formula of $\left(\mathrm{Mg}_{0.46} \mathrm{Fe}^{3}\right.$ $\left.{ }_{0.53}\right)\left(\mathrm{Si}_{0.49} \mathrm{Fe}^{3+}{ }_{0.51}\right) \mathrm{O}_{3}$.

Spin transition of ferric iron in Bdg. Complementary XRD and XES results show that the spin transition of $\mathrm{Fe}^{3+}$ in the Bsiteoccurs between 43 and $53 \mathrm{GPa}$ at $300 \mathrm{~K}$ in $\left(\mathrm{Mg}_{0.46} \mathrm{Fe}^{3+}{ }_{0.53}\right)$ $\left(\mathrm{Si}_{0.49} \mathrm{Fe}^{3+}{ }_{0.51}\right) \mathrm{O}_{3}$ Bdg (Figs. 2 and 3). Over this pressure range, the compressibility of this Bdg increases sharply and the unit cell volume decreases by about $1.9 \%$ (Fig. 2 and Supplementary Table 2). This softening is clear in the decrease in the normalized stress $F$ (Fig. 2, inset), which is sensitive to magnetic and spin transitions under pressure ${ }^{36}$. At pressures below $43 \mathrm{GPa}$ and above $53 \mathrm{GPa}$, the slope of $F$ vs. Eulerian strain $f$ is almost 0 , indicating that the pressure derivative of bulk modulus $\left(K^{\prime}\right)$ is nearly 4 and a second order Birch-Murnaghan EoS suffices for fitting these two segments (Fig. 2). Relative to $\mathrm{HS} \mathrm{Fe}^{3+}$-bearing Bdg, LS Bdg exhibits $2.7 \%$ smaller ambient-pressure volume, $V_{0}$,

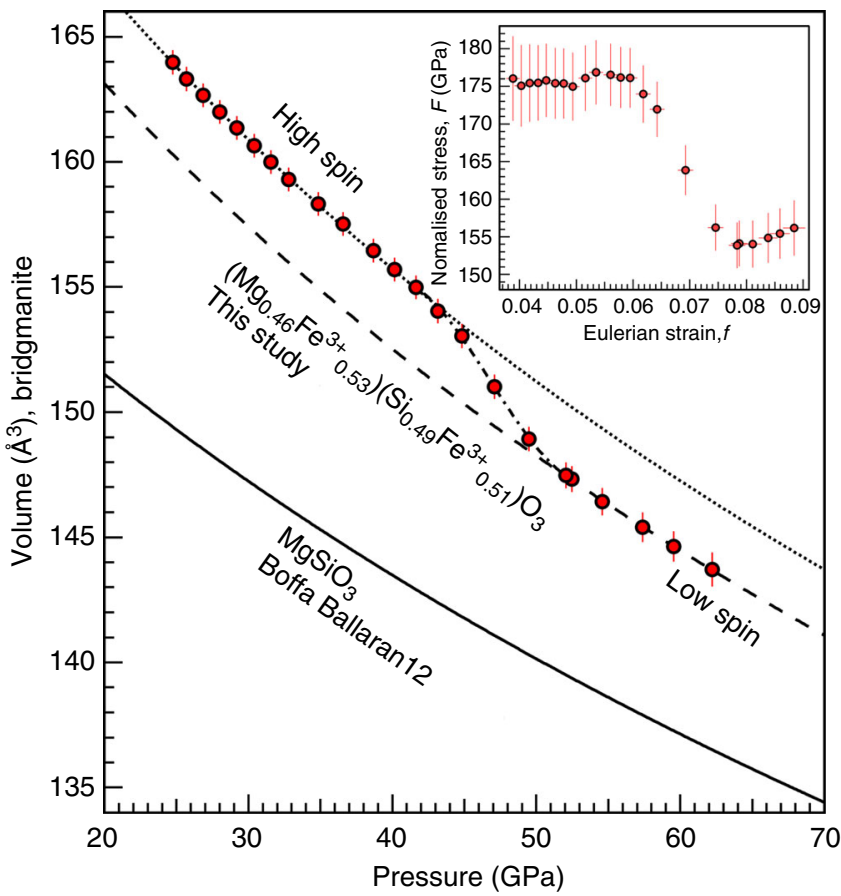

Fig. 2 Compression behavior of bridgmanite (Bdg) at $300 \mathrm{~K}$ across the spin transition. An unit cell volume of $\left(\mathrm{Mg}_{0.46} \mathrm{Fe}^{3+}{ }_{0.53}\right)\left(\mathrm{Si}_{0.49} \mathrm{Fe}^{3+}{ }_{0.51}\right) \mathrm{O}_{3} \mathrm{Bdg}$ and second order Birch-Murnaghan equation of state fits to the high-spin data between 24.7 and $43.1 \mathrm{GPa}$ (dotted) and 50\% low-spin data between 52.5 and $61.4 \mathrm{GPa}$ (dashed). Softening is observed between 43.1 and 52.5 $\mathrm{GPa}$ (dot dashed). The compression curve of $\mathrm{MgSiO}_{3} \mathrm{Bdg}$ is also plotted for comparison (black curve ${ }^{38}$ ). Inset: normalized stress $F$ vs. Eulerian strain $f$ calculated using the fitted 1-bar unit cell volume from the lower pressure segment, revealing a discontinuity between 43.1 and $52.5 \mathrm{GPa}$. The error bars are $95 \%$ confidence intervals and $5.7 \%$ higher ambient-pressure bulk modulus, $K_{0}$ (Supplementary Table 3 ). The spin transition in our Bdg is confirmed by XES measurements up to $85 \mathrm{GPa}$ at $300 \mathrm{~K}$ (Fig. 3a). A total spin moment decreases from a maximum of 2.5 , corresponding to $100 \% \mathrm{HS} \mathrm{Fe} \mathrm{F}^{3+}$, to a minimum of about 1.5 (Fig. $3 \mathrm{~b}$ ), corresponding to $50 \% \mathrm{HS}, 50 \% \mathrm{LS} \mathrm{Fe} \mathrm{Fe}^{3+}$, over the range $40-60 \mathrm{GPa}$ (Fig. 3b).

The observed spin transition pressure and volume collapse provide robust confirmation for recent density functional theory calculations and resolve disagreement among previous experimental studies. Theoretical computation ${ }^{26}$ found a spin transition in $\mathrm{B}$-site $\mathrm{Fe}^{3+}$ at $48-56 \mathrm{GPa}$ and $0 \mathrm{~K}$ for a similar composition $\left(\mathrm{Mg}_{0.5} \mathrm{Fe}^{3+}{ }_{0.5}\right)\left(\mathrm{Si}_{0.5} \mathrm{Fe}^{3+}{ }_{0.5}\right) \mathrm{O}_{3}$. For this composition, no prediction of the effect of the spin transition on the EoS is available, but for a less-enriched $\left(\mathrm{Mg}_{0.875} \mathrm{Fe}_{0.125}\right)\left(\mathrm{Si}_{0.875} \mathrm{Fe}_{0.125}\right) \mathrm{O}_{3} \mathrm{Bdg}$ the spin transition was predicted to result in a volume collapse of $0.5 \%{ }^{37}$ or $1.2 \%{ }^{23}$. The lower bound predicted for $\Delta V$ is consistent with our observations (Fig. 2), assuming a linear relation between $\Delta V$ and iron content. In comparison, Mao et al. ${ }^{24}$ reported a $0.5 \%$ reduction in unit cell volume at $18-25 \mathrm{GPa}$ with $0.02 \mathrm{Fe}^{3+}$ per formula unit, which is higher but comparable with theoretical prediction $^{26}$. Theoretical calculations predict that the spin transition in $\mathrm{A}$-site $\mathrm{Fe}^{3+}$ happens at much higher pressures than the transition in the B-site ${ }^{23}$; therefore, the $50 \% \mathrm{LS} \mathrm{Fe}^{3+}$ derived from our XES data is consistent with the transition of only B-site $\mathrm{Fe}^{3+}$ to the LS state at the lower mantle pressures. Previous experimental studies disagreed on the spin transition pressure range: a subtle change in the EoS was reported in a recent study at $18-25 \mathrm{GPa}^{24}$, while two other studies found less obvious discontinuities in bulk modulus around $50-70 \mathrm{GPa}^{21,22}$. Other experimental studies observed no spin transition at all (e.g., refs. 38,39 ). Differences between observed spin transition pressures are unlikely to be explained by compositional differences alone as had been suggested by computational work ${ }^{26}$ : our sample exhibits a spin transition pressure in-between reported pressures in previous experiments on Bdg but has the highest $\mathrm{Fe}^{3+}$ content. Different experimental protocols and possible diffusion or reduction of iron during high-temperature experiments could cause the discrepancy. Well-characterized Bdg samples synthesized in the multi-anvil apparatus often incorporate all Fe in the A-site(e.g., refs. ${ }^{24,38}$ ), and would not be expected to undergo spin transitions under the mantle pressures. Many other studies do not have strong constraints on the valence state or site occupancy of $\mathrm{Fe}$ in $\mathrm{Bdg}$, but it is likely that failure to observe spin transitions indicates that no $\mathrm{Fe}^{3+}$ is present in the B-site. Moreover, some Bdg samples synthesized using laser heated DACs exhibit excess $\mathrm{SiO}_{2}$, indicating that the composition of synthesized Bdg differs from the starting material. Upon heating, cations may also be oxidized or reduced and/or migrate between the two crystallographic sites ${ }^{40}$, and thus some apparent changes in compressibility may be due to different crystal chemistry. Our EoS and XES data obtained on well-characterized samples without any heating during compression provide support for theoretical predictions $^{23,25,26,37}$ and experimental observations ${ }^{21,22}$ that at lower mantle pressures, $\mathrm{A}$-site $\mathrm{Fe}^{3+}$ remains in HS state and $\mathrm{B}$ site $\mathrm{Fe}^{3+}$ undergoes the HS-LS transition.

For iron-rich compositions, the elastic properties and spintransition-induced softening in $\mathrm{Fe}^{3+}-\mathrm{Bdg}$ can be easily distinguished from elastic properties of $\mathrm{Fe}^{2+}$-dominant $\mathrm{Bdg}$, but for mantle-relevant amounts of iron this difference becomes insignificant (Fig. 4). With the highest Fe content among synthesized $\mathrm{Bdg}$, our $\mathrm{Fe}^{3+}$-only Bdg has the largest unit cell observed to date for Bdg below the pressures of the spin transition (Supplementary Fig. 4). Above the spin transition pressures of $\mathrm{B}$-site $\mathrm{Fe}^{3+}$, the unit cell volume of our $\mathrm{Fe}^{3+}-\mathrm{Bdg}$ collapses to match volumes of $\mathrm{Fe}^{2+}$-dominant Bdg with similar total Fe content (Supplementary 

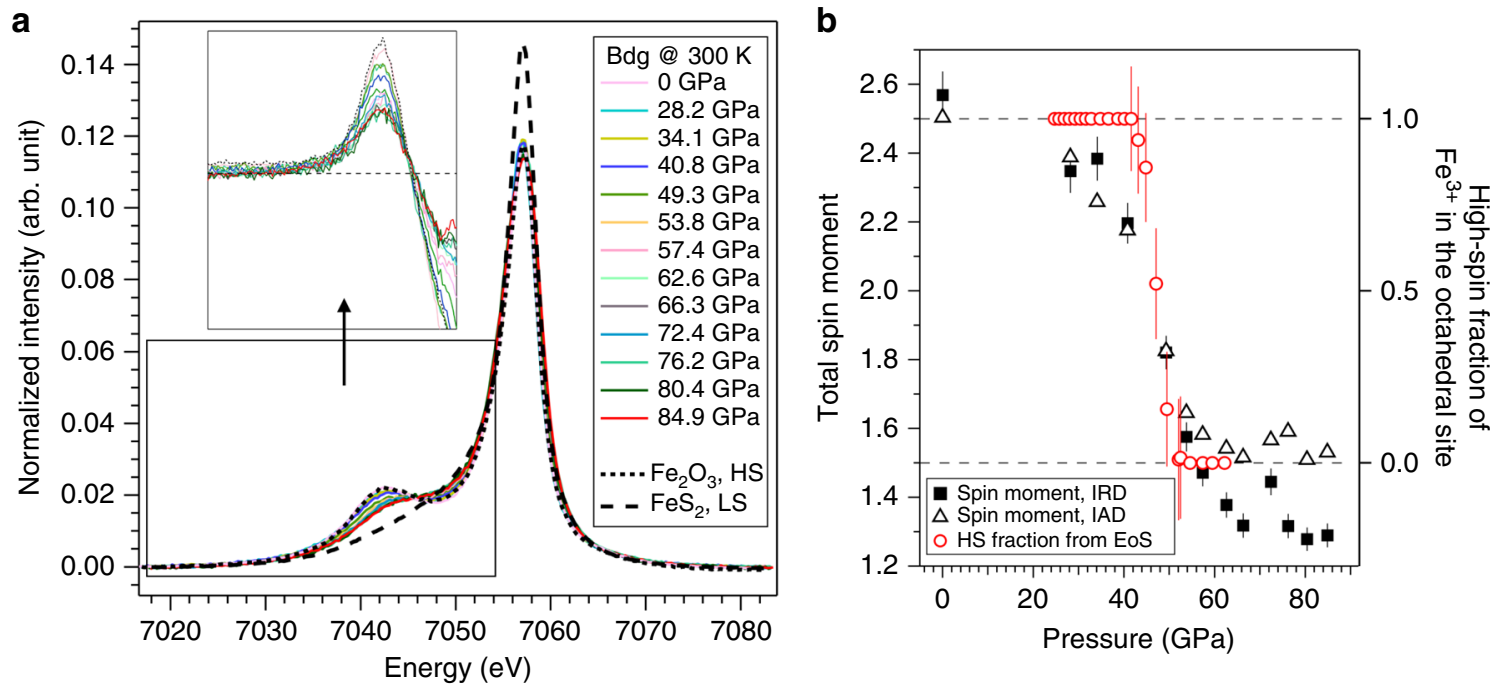

Fig. 3 X-ray emission Fe $K_{\beta}$ spectra and total spin moment. a XES data for $\left(\mathrm{Mg}_{0.46} \mathrm{Fe}^{3+}{ }_{0.53}\right)\left(\mathrm{Si}_{0.49} \mathrm{Fe}^{3+}{ }_{0.51}\right) \mathrm{O}_{3}$ bridgmanite up to $84.9 \mathrm{GPa}$ at $300 \mathrm{~K}$. All spectra were normalized to area and aligned to position of the main peak. Both the spectra of $\mathrm{Fe}_{2} \mathrm{O}_{3}$ and the sample at 1 bar served as the high-spin (HS) reference, while $\mathrm{FeS}_{2}$ at 1 bar was used as the low-spin (LS) reference. The inset shows the difference between the sample spectra and the LS reference $\mathrm{FeS}_{2}$. b The total spin moment (left axis) derived from both integrated absolute difference (IAD, open triangles) and integrated relative difference (IRD, black squares) methods ${ }^{68}$ as a function of pressure. Error bars were determined by evaluating the difference in calculated spin moment using either Fe $\mathrm{O}_{3}$ or ambient $\mathrm{Mg}_{0.46} \mathrm{Fe}^{3+}{ }_{1.04} \mathrm{Si}_{0.49} \mathrm{O}_{3}$ sample as the $\mathrm{HS}$ standard. The expected spin moment for HS-only configuration is 2.5 (marked by the upper horizontal dashed line), while the B-site spin transition should lower total spin moment to 1.5 (marked by the lower horizontal dashed line). The red open circles are $\mathrm{HS}$ fractions of B-site $\mathrm{Fe}^{3+}$ (right axis) derived from equation of state (EOS) under high pressures. Error bars of HS fractions obtained from EoS represent $95 \%$ confidence interval in EOS parameters $V_{\mathrm{HS}}, V_{\mathrm{LS}}, K_{\mathrm{HS}}$, and $K_{\mathrm{LS}}{ }^{32}$. XES and XRD concur that spin transition of $\mathrm{B}$-site $\mathrm{Fe}^{3+}$ is centered at $48-49 \mathrm{GPa}$ at ambient temperature

Fig. 4). Consequently, redox heterogeneity cannot be determined from density heterogeneity once the spin transition of B-site $\mathrm{Fe}^{3+}$ is complete in the deep lower mantle (Fig. 4a and Supplementary Fig. 5). The bulk moduli $K$ of both HS and LS $\mathrm{Fe}^{3+}$-rich Bdg are lower than that of $\mathrm{Fe}^{2+}$-dominant Bdg (Fig. 4b). At a representative mid-lower mantle pressure of $80 \mathrm{GPa}$ (corresponding to a depth of $1850 \mathrm{~km}), K$ of $\mathrm{HS}\left(\mathrm{Mg}_{0.46} \mathrm{Fe}^{3+}{ }_{0.53}\right)$ $\left(\mathrm{Si}_{0.49} \mathrm{Fe}^{3+}{ }_{0.51}\right) \mathrm{O}_{3}$ Bdg is $11.1 \%$ lower than the extrapolated $K$ for $\mathrm{FeSiO}_{3} \mathrm{Bdg}$, and $K$ of $\left(\mathrm{Mg}_{0.46} \mathrm{Fe}^{3+}{ }_{0.53}\right)\left(\mathrm{Si}_{0.49} \mathrm{Fe}^{3+}{ }_{0.51}\right) \mathrm{O}_{3} \mathrm{Bdg}$ with $\mathrm{B}$-site $\mathrm{LS} \mathrm{Fe}^{3+}$ is $9.3 \%$ lower than that of $\mathrm{FeSiO}_{3} \mathrm{Bdg}$ (Fig. 4b). The magnitudes of these differences in $K$ are comparable to softening caused by A-site vacancy ${ }^{41}$. The corresponding bulk sound velocity for $\mathrm{Fe}^{3+}$-dominant $\mathrm{Bdg}$ exhibits a similar trend as bulk modulus (Fig. 4c). The heterogeneity parameter $\partial \ln V_{\mathrm{B}} / \partial X_{\mathrm{Fe}}$ for $\mathrm{Fe}^{3+}{ }_{-} \mathrm{Bdg}$ is 0.15 ; this is 1.5 times of the 0.1 obtained for $\mathrm{Fe}^{2+}$-dominant $\mathrm{Bdg}^{19}$, resulting in a stronger velocity anomaly for an oxidized mantle heterogeneity. If interpolated to a typical mantle composition with iron content $2 \mathrm{Fe} /(\mathrm{Mg}+\mathrm{Fe}+\mathrm{Al}+\mathrm{Si}) \sim 0.1$ in $\mathrm{Bdg}^{42}$, differences in density, bulk modulus, and bulk sound velocity between reduced and oxidized $\mathrm{Bdg}$ at $80 \mathrm{GPa}$ are up to $0.3 \%$, $1.1 \%$, and $0.5 \%$, respectively. These small differences have been within experimental uncertainties for studies with less $\mathrm{Fe}$, but can be resolved by our study of well-characterized Fe-rich Bdg samples with careful high-pressure experimental design. Given the fact that lower mantle temperatures would reduce the difference in density and sound velocity between $\mathrm{Fe}^{2+}$ - and $\mathrm{Fe}^{3}$ ${ }_{+}^{+}$bearing bdg, reduced and oxidized Bdg with mantle-relevant iron content will exhibit almost identical seismic velocities in the deep lower mantle.

For a given concentration of $\mathrm{Fe}$, the presence of $\mathrm{Al}$ in $\mathrm{Bdg}$ has been observed to have relatively minor effects on density and bulk modulus $^{19,25}$ (Fig. 4) and may suppress the spin transition by occupying the B-site(see Implications below). As a result, experiments on $\mathrm{Fe}$, Al-bearing compositions have been unable to unambiguously determine whether and under what conditions spin transitions take place in the mantle. The effects of spin and valence states of $\mathrm{Fe}$ on density and bulk compressibility are expected to be even less significant in Al-bearing lithologies in the mantle. Although shear properties cannot be constrained by our experimental data, theoretical calculations have predicted that the effects of trivalent cations and/or spin transition of the B-site $\mathrm{Fe}^{3}$ + on shear modulus are even smaller than on bulk modulus ${ }^{25}$. Therefore, the incorporation of trivalent cations in $\mathrm{Bdg}$ is not expected to cause obvious elastic anomalies in the lower mantle.

An independent constraint on mantle compositional and thermal heterogeneities can be obtained from lower mantle electrical conductivity. Current electrical conductivity models based on geomagnetic observations show a smooth profile of electrical conductivity with depth in the lower mantle ${ }^{11,12}$. This profile appears to be inconsistent with spin transitions of iron in lower mantle minerals because such a transition reduces the number of unpaired electrons, resulting in a decrease in the mobility and density of the electric charge carriers and a potentially observable decrease in electrical conductivity. The decrease in conductivity due to the spin transition has been observed in $\mathrm{Fp}^{43,44}$, but has been unclear for $\mathrm{Bdg}^{34,45,46}$. Ohta et al. $^{45}$ reported a $\sim 0.5$ order of magnitude decrease in electrical conductivity at 70-85 GPa in $\left(\mathrm{Mg}_{0.9} \mathrm{Fe}_{0.1}\right) \mathrm{SiO}_{3} \mathrm{Bdg}$ and attributed this anomaly to the spin transition of $\mathrm{Fe}^{3+}$, but two more recent studies reported monotonic increase in electrical conductivity of Bdg under the lower mantle pressures ${ }^{34,46}$ (Fig. 5), which are more consistent with electrical conductivity models ${ }^{11,12}$. In order to clarify the influence of spin transition on the electrical conductivity of Bdg, we determined the electrical conductivity of our Bdg sample by using a four-point-probe method (Supplementary Fig. 6). Note that this method is only applicable to Bdg compositions, which can be either recovered or synthesized 

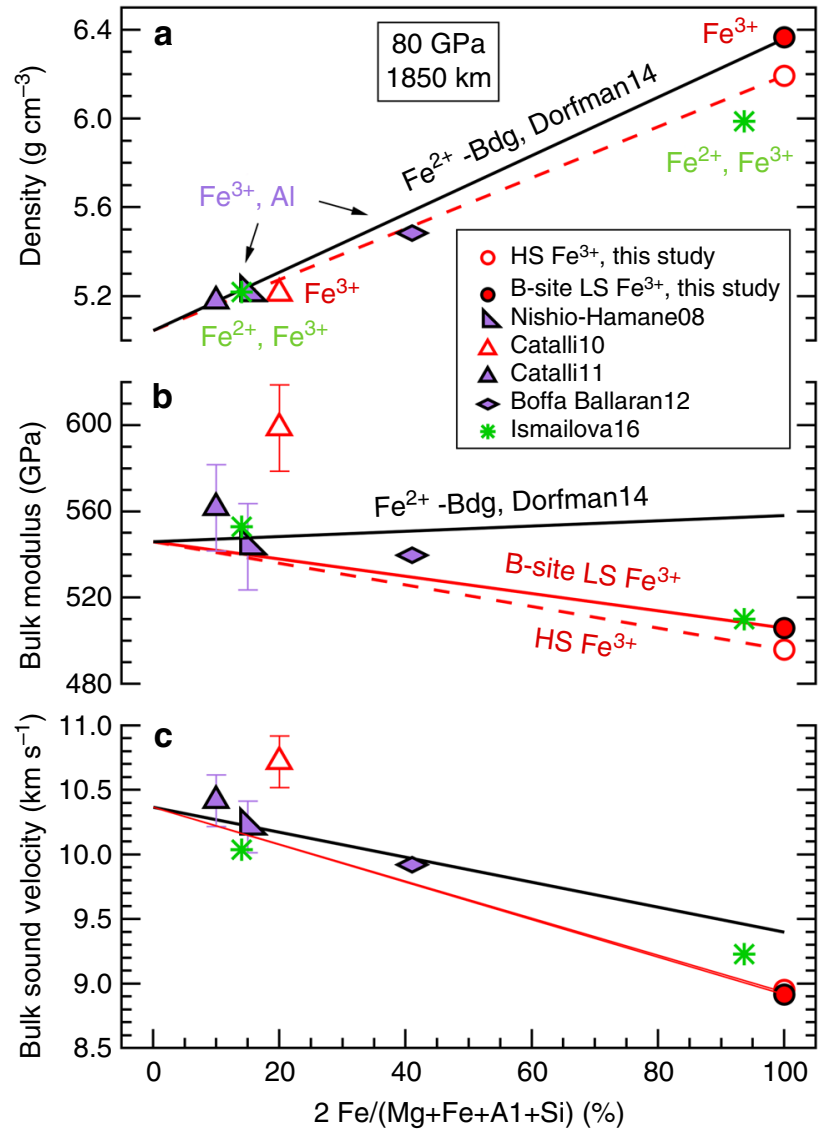

Fig. 4 Variation of observable seismic properties of bridgmanite as a function of iron content at $80 \mathrm{GPa}$ and $300 \mathrm{~K}$. EoS results from this study and previous work summarized in ref. ${ }^{19}$ demonstrate that $\mathbf{a}$ density $\mathbf{b}$ bulk modulus, and $\mathbf{c}$ bulk sound velocity exhibit different dependence on $\mathrm{Fe}^{2+}$ and $\mathrm{Fe}^{3+}$ content. The red solid lines are linear interpolations between $\mathrm{MgSiO}_{3}-\mathrm{Bdg}$ and end members for high-spin (HS) $\mathrm{Fe}^{3+}-\mathrm{Bdg}$ and the red dashed lines are those for $\mathrm{B}$-site low-spin (LS) $\mathrm{Fe}^{3+} \mathrm{Bdg}$. The black lines are linear fits for $\mathrm{Fe}^{2+}-\mathrm{Bdg}$ summarized in ref. ${ }^{19}$. The $\mathrm{Fe}^{3+}-\mathrm{Bdg}$ end member is from this study, and the open and solid circles are for $\mathrm{HS}$ and B-site LS Fe ${ }^{3+}$ $\mathrm{Bdg}$, respectively. Differences between ${ }^{21}$ (red triangles) and solid red line trend for bulk modulus and sound velocity may be caused by compositional changes during Bdg synthesis from glass in the laser heated diamond anvil cell. The purple symbols are for $\mathrm{Fe}^{3+}, \mathrm{Al}$-bearing Bdg samples ${ }^{22,70}$, and the green symbols are for $\mathrm{Fe}^{3+}, \mathrm{Fe}^{2+}$-bearing $\mathrm{Bdg}$ samples with $\mathrm{Fe}^{3+} / \Sigma \mathrm{Fe}$ $<50 \% 41$

without laser heating, as $\mathrm{Au}$ probes must be attached at ambient conditions to homogeneous samples. The 300-K akimotoite-Bdg transition provides an entirely new route to access electrical properties of $\mathrm{Fe}^{3+}$-bearing Bdg. Our results show that the pressure range of spin transition in $\mathrm{B}$-site $\mathrm{Fe}^{3+}$ coincides with a subtle decrease of $0.18-0.29 \mathrm{log}$ unit in electrical conductivity (Fig. 5), and this decrease in conductivity was reproduced in two successive experiments using the same DAC. On the other hand, the electrical conductivity of B-site LS $\mathrm{Fe}^{3+} \mathrm{Bdg}$ is only slightly lower than extrapolated values from the HS segment (Fig. 5), revealing much lower reduction of electrical conductivity by spin transition in Bdg than $\mathrm{Fp}^{43,44}$. Given the fact that Fe content in the lower mantle is about one tenth of that in our sample (e.g., ref. 42 ) and mantle temperatures would further weaken or broaden the effects of the spin transition, our results demonstrate that the spin transition of $\mathrm{B}$-site $\mathrm{Fe}^{3+}$ of $\mathrm{Bdg}$ in the lower mantle has a negligible effect on electrical conductivity of the mantle, which is

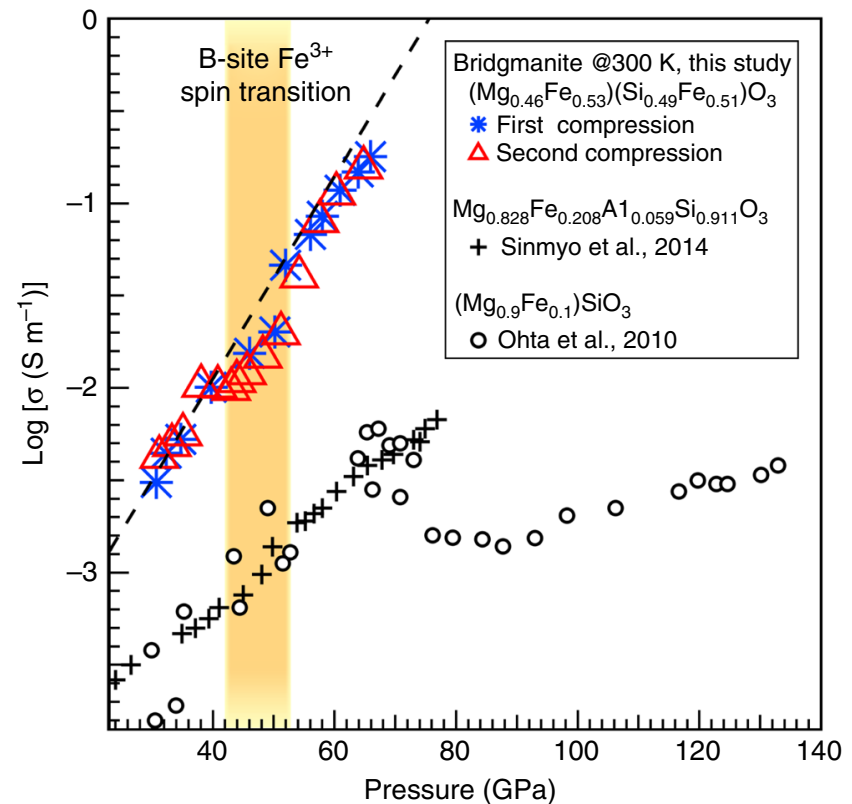

Fig. 5 The electrical conductivity of three bridgmanite compositions across the spin transition at high pressures and $300 \mathrm{~K}$. The red open triangles and blue asterisks are for $\left(\mathrm{Mg}_{0.46} \mathrm{Fe}^{3+}{ }_{0.53}\right)\left(\mathrm{Si}_{0.49} \mathrm{Fe}^{3+}{ }_{0.51}\right) \mathrm{O}_{3} \mathrm{Bdg}$ along two successive compression paths by using the same DAC. The uncertainty is smaller than the symbol size. The yellow region marks the pressure range (43-53 GPa) of the spin transition in the B-site $\mathrm{Fe}^{3+}$, in this study constrained by complementary XRD and XES measurements. The dashed line is a linear fit to the electrical conductivity data up to $40 \mathrm{GPa}$, which predicts slightly higher conductivity than measured data above $54 \mathrm{GPa}$. Between 40 and $54 \mathrm{GPa}$, there is a 0.18-0.29 log unit drop in electrical conductivity as a result of spin transition in the $\mathrm{B}$-site $\mathrm{Fe}^{3+}$. In comparison, Ohta et al. ${ }^{45}$ reported a more significant drop ( 0.5 log unit) between 70 and $85 \mathrm{GPa}$ in $\left(\mathrm{Mg}_{0.9} \mathrm{Fe}_{0.1}\right) \mathrm{SiO}_{3} \mathrm{Bdg}$ (black open circles). In contrast to ref. $^{45}$, ref. ${ }^{46}$ reported much smoother conductivity profile for $\mathrm{Mg}_{0.828} \mathrm{Fe}_{0.208} \mathrm{Al}_{0.059} \mathrm{Si}_{0.911} \mathrm{O}_{3} \mathrm{Bdg}$. Note that the conductivity trend from ref. $^{46}$ also exhibits a dip within the spin transition pressure range from this study

consistent with the smooth profile obtained from geophysical observations ${ }^{11,12}$.

\section{Discussion}

Whether a spin transition occurs in Bdg in Earth's mantle has been subject to debate due both to observed smooth variation in geophysical properties and uncertainty in the crystal chemistry of $\mathrm{Fe}$ in $\mathrm{Bdg}$. The $\mathrm{Fe}^{3+} / \Sigma \mathrm{Fe}$ ratio of Bdg in the lower mantle has been estimated based on sound velocity of Bdg obtained by experimental $^{47}$ and theoretical methods ${ }^{48}$ to range from $60 \%$ to even $90 \%$. This high $\mathrm{Fe}^{3+}$ content relative to the upper mantle could be explained by $\mathrm{Fe}^{2+}$ self-disproportionation to $\mathrm{Fe}^{3+}$ and metallic Fe during the formation of Bdg beneath the transition zone ${ }^{49}$. $\mathrm{Al}^{3+}$ facilitates $\mathrm{Fe}^{3+}$-enrichment in lower mantle $\mathrm{Bdg}$ through the coupled-substitution mechanism $\left(\mathrm{Mg}^{2+}{ }_{\mathrm{A}}+\mathrm{Si}^{4+}{ }_{\mathrm{B}}=\right.$ $\left.\mathrm{Fe}^{3+}{ }_{\mathrm{A}}+\left(\mathrm{Fe}^{3+}, \mathrm{Al}^{3+}\right)_{\mathrm{B}}\right)$ (e.g., refs. $\left.{ }^{49,50}\right)$. Whether $\mathrm{Fe}^{3+}$ enters the $\mathrm{B}$-site of Bdg through this coupled-substitution mechanism and further undergoes the spin transition in the lower mantle depends on the concentration of cations available to fill the B-site of Bdg and $P-T$ conditions. For Bdg samples synthesized from pyrolitic starting materials representing a lower mantle lithology, observed $\mathrm{Al} / \mathrm{Fe}^{3+}$ ratios are consistently greater than 1 (summarized in ref. $\left.{ }^{51}\right)$. In this compositional regime, all $\mathrm{Fe}^{3+}$ is predicted to occupy the A-site, while $\mathrm{Al}^{3+}$ fills the rest of the A-site and all of the 
smaller B-site(e.g., refs. ${ }^{52,53}$ ) and therefore no spin transition of $\mathrm{Fe}^{3+}$ is expected to take place in the B-site of Bdg in a pyrolitic lower mantle. Some recent experimental studies suggest that cation exchange between $\mathrm{A}$-site $\mathrm{Fe}^{3+}$ and $\mathrm{B}$-site $\mathrm{Al}^{3+}$ becomes more favorable at high $P-T$ conditions, driven by the volume collapse across the spin transition of the $\mathrm{B}$-site $\mathrm{Fe}^{3+}$ (ref. ${ }^{22,40,51,54}$ ). On the other hand, site exchange is not supported by theoretical calculations, which predict very limited migration of $\mathrm{A}$-site $\mathrm{Fe}^{3+}$ to the $\mathrm{B}$-site $(<\sim 4 \%)$ throughout the lower mantle $P-T$ conditions $(54,55)$. These studies and a recent experimental study on single-crystal Bdg ${ }^{55}$ suggest that $\mathrm{Fe}^{3+}$ in the B-site of Fe, Al-bearing Bdg is metastable and therefore most Bdg in Earth's mantle may contain no $\mathrm{Fe}^{3+}$ in the B-site. Even in the absence of $\mathrm{Fe}-\mathrm{Al}$ site exchange, however, multiple scenarios could give rise to domains in the mantle where the experimentally observed $\mathrm{Fe}^{3+}$ spin transition occurs in Bdg. First, in Al, Si-poor, oxidized lithology, $\mathrm{Fe}^{3+}$ may be forced into the Bdg B-site. For example, subducted harzburgite is depleted in $\mathrm{Al}$ with $\mathrm{Al} / \mathrm{Fe}$ as low as $0.18^{56}$. If there is not enough $\mathrm{Al}+\mathrm{Si}$ to fill the $\mathrm{Bdg} \mathrm{B}$-site, $\mathrm{Fe}^{3+}$ may be driven by crystal chemistry to adopt this site ${ }^{57}$. Moreover, $\mathrm{Fe}^{3+}$-rich materials, such as banded iron formation and goethite, could also be carried to the lower mantle by subducted slabs and would provide local chemical heterogeneous regions enriched in $\mathrm{Fe}^{3+}$, with a high $\mathrm{Fe}^{3+} / \mathrm{Al}$ ratio. Second, $\mathrm{Fe}^{3+}$ may take the B-site of Bdg as a result of metastable arrangement of Fe during fast crystallization of melts in partially molten (hot and/or hydrous) regions. While spin transition in Bdg likely occurs in regions with either subducted $\mathrm{Fe}^{3+}$-rich, Al-poor lithologies, or fast/metastable crystallization, our results demonstrate that a spin transition in these regions would not have a major effect on seismic velocities or electrical conductivity, but could influence other geophysical or geochemical processes.

Spin transitions have been suggested to weaken the lower mantle phase assemblage ${ }^{32,33,58}$, offering a potential explanation for a viscosity minimum around $1600-2500 \mathrm{~km}$ depth inferred by geoid inversion studies ${ }^{9,10}$, which may affect dynamics of subducted slabs and hot upwelling plumes ${ }^{59,60}$. However, studies of effects of spin transitions on deformation of lower mantle minerals have been limited to $\mathrm{Fp}^{32,33,58}$. Fp likely comprises $<20 \%$ of the lower mantle phase assemblage and will only have a significant effect on viscosity if grains are interconnected. If the lower mantle is enriched in $\mathrm{Si}$ and adopts equilibrium texture $^{61,62}$, Bdg is the interconnected phase that will control deformation. Due to the high strength of Bdg relative to $\mathrm{Fp}^{63}$, the viscosity of a dominantly Bdg lower mantle is high. Based on our experimental observations, the spin transition in $\mathrm{Fe}^{3+}$-dominant Bdg occurs at similar depths and induces comparable reduction in both bulk modulus and bulk velocity as Fp (Supplementary Fig. 7). As a result, the spin transition in Bdg may also cause a comparable change in viscosity ${ }^{32,33}$. The decrease in viscosity during the spin transition and increase at higher pressures matches the observed broad valley in lower mantle viscosity profile with the minimum at about $1600-2500 \mathrm{~km}^{9,10}$. Together with the notion that the lower mantle may be more enriched in Bdg than previous estimation ${ }^{18,61,62}$, the spin transition in $\mathrm{Fe}^{3+}$-bearing Bdg thus may play an important role in controlling lower mantle dynamics.

With this new robust constraint on the $\mathrm{EoS}$ of $\mathrm{Fe}^{3+}$-bearing Bdg, we can conclude that redox effects on bulk modulus and density of Bdg for normal mantle compositions are not detectable in the deep mantle by current geophysical methods (Fig. 4). The difference between physical properties of Bdg with $\mathrm{HS} \mathrm{Fe}^{2+}$, HS $\mathrm{Fe}^{3+}$, LS $\mathrm{Fe}^{3+}$, or even mixed spin $\mathrm{Fe}^{3+}$ at lower mantle conditions is too small to be resolved by seismology. Along the lower mantle geotherm, the pressure range of the spin transition of the $\mathrm{B}$-site $\mathrm{Fe}^{3+}$ in Bdg is broadened by about $30 \mathrm{GPa}^{25,26}$, meaning that a mixture of $\mathrm{HS}$ and LS B-site $\mathrm{Fe}^{3+}$ in $\mathrm{Bdg}$ would coexist over $\sim 800 \mathrm{~km}$ depth range. Although the mixed spin state of the $\left(\mathrm{Mg}_{0.46} \mathrm{Fe}^{3+}{ }_{0.53}\right)\left(\mathrm{Si}_{0.49} \mathrm{Fe}^{3+}{ }_{0.51}\right) \mathrm{O}_{3} \mathrm{Bdg}$ in this study at $300 \mathrm{~K}$ causes decrease of the bulk modulus (52\%) and bulk sound speed (31\%) (Supplementary Fig. 7), the temperature-induced broadening and lower $\mathrm{Fe}^{3+}$-content in lower mantle Bdg will together decrease the magnitudes of the softening by $\sim 100$ times for lower mantle compositions and temperatures ${ }^{25,26}$. The mixed spin state in ferric but not ferrous Bdg provides the strongest signal for potentially observing contrast in $V_{\mathrm{B}}$ between oxidized and reduced Bdg. If seismic tomography techniques improve precision in resolution of $V_{\mathrm{B}}$ to $0.5 \%$, valence states of iron in mantle Bdg could be resolved; for sensitivity to spin state, a precision closer to $0.01 \%$ would be required beneath about $1850 \mathrm{~km}$ (Fig. 4). For $\mathrm{Mg} \#=\mathrm{Mg} /(\mathrm{Mg}+\mathrm{Fe})=90 \mathrm{Bdg}$ representative of the mantle, differences in oxidation state of iron result in a density difference up to $\sim 0.3 \%$ (Fig. 4), far less than the $1.5-2 \%$ redoxinduced density contrast required to rapidly separate oxidized materials from reduced materials in the early history of the Earth $^{20}$. Moreover, the spin-transition-induced density increase makes the density contrast of Bdg with different $\mathrm{Fe}^{3+} / \Sigma \mathrm{Fe}$ ratios sharply fade away below the mid-mantle depth (Fig. 4 and Supplementary Fig. 5). Recent experimental and theoretical studies show that the $\mathrm{Fe}^{3+} / \Sigma \mathrm{Fe}$ ratio of $\mathrm{Bdg}$ is not constant but varies significantly across the lower mantle $P-T$ conditions ${ }^{47,48}$. Given the smooth density and sound velocity profiles of the lower mantle ${ }^{31}$, the minor influence of both spin and valence states of iron in Bdg on its elastic properties may reconcile geophysical observations and mineral physics. Since both spin and valence states of iron in Bdg are invisible to seismic tomography, other mechanisms are required to explain observed lower mantle heterogeneities, such as a combination of regional enrichment in iron and deficiency in silicon ${ }^{17,62}$.

\section{Methods}

Bdg synthesis. Samples were synthesized from a mixture of approximately 1:1:1 molar ratios high purity (>99.99\%) $\mathrm{Fe}_{2} \mathrm{O}_{3}, \mathrm{MgO}$, and $\mathrm{SiO}_{2}$ at $24 \mathrm{GPa}$ and $1873 \mathrm{~K}$ for about $9 \mathrm{~h}$ using the multi-anvil apparatus at the University of Michigan. The resulting akimotoite was quenched from high temperature and slowly decompressed. ${ }^{57} \mathrm{Fe}$-enriched akimotoite was synthesized by the same method using ${ }^{57} \mathrm{Fe}_{2} \mathrm{O}_{3}\left({ }^{57} \mathrm{Fe} 94.3 \%\right)$ instead. The average composition of the recovered magnesium silicate samples is $\mathrm{Mg}_{0.46(2)} \mathrm{Fe}_{1.04(1)} \mathrm{Si}_{0.49(1)} \mathrm{O}_{3}$, based on electron microprobe analysis (SX-100; focused beam; accelerating voltage of $15 \mathrm{keV}$ and beam current of $10 \mathrm{nA}$; forsterite $\left(\mathrm{Mg}_{2} \mathrm{SiO}_{4}\right)$ was used as $\mathrm{Mg}$ and $\mathrm{Si}$ standard, while magnetite

$\left(\mathrm{Fe}_{3} \mathrm{O}_{4}\right)$ was used as Fe standard. Minor amounts of $\mathrm{Mg}_{1.2(1)} \mathrm{Fe}_{3.8(1)} \mathrm{O}_{7}$ were found along grain boundaries of Bdg sample (Supplementary Fig. 1) and this phase may adopt the same structure as recently reported $\mathrm{Fe}_{5} \mathrm{O}_{7}{ }^{64}$. The ambient XRD pattern of $\mathrm{Mg}_{0.46(2)} \mathrm{Fe}_{1.04(1)} \mathrm{Si}_{0.49(1)} \mathrm{O}_{3}$ sample matches $R \overline{3}$ ilmenite structure with no contamination from the minor $\mathrm{Mg}_{1.2(1)} \mathrm{Fe}_{3.8(1)} \mathrm{O}_{7}$ phase. The ambient unit cell volume of our akimotoite sample is $282.8 \mathrm{~A}^{3}$, consistent with $50 \%$ linear mixing between reported volumes for the isostructural $R \overline{3}$ end members $\mathrm{Fe}_{2} \mathrm{O}_{3}{ }^{64}$ and $\mathrm{MgSiO}_{3}{ }^{65}$ $\mathrm{Mg}_{0.46(2)} \mathrm{Fe}_{1.04(1)} \mathrm{Si}_{0.49(1)} \mathrm{O}_{3}$ akimotoite transforms to $\mathrm{Bdg}$ at $\sim 24 \mathrm{GPa}$ and $300 \mathrm{~K}$ and is fully recovered to ilmenite structure with the same lattice parameters as the initial values after decompression. As a result, the composition of the Bdg phase should be the same as akimotoite and the stoichiometric chemical formula of our Bdg sample is written as $\left(\mathrm{Mg}_{0.46} \mathrm{Fe}_{0.53}\right)\left(\mathrm{Si}_{0.49} \mathrm{Fe}_{0.51}\right) \mathrm{O}_{3}$

DAC experiments. Akimotoite samples were prepared for high-pressure experiments in symmetric-type DACs with pairs of $300-\mu \mathrm{m}, 200-\mu \mathrm{m}$ flat diamonds for pressure ranges up to 65.9 and $84.9 \mathrm{GPa}$, respectively. The sample chambers were confined by rhenium gaskets for XRD and hybrid-mode time-domain SMS measurements, while an X-ray transparent beryllium gasket was used for XES measurements. The gaskets were preindented to $\sim 30 \mu \mathrm{m}$ and then sample chambers with diameters approximately halves of the culet sizes were machined using the laser drilling system at HPCAT (Sector 16) of the Advanced Photon Source (APS), Argonne National Laboratory (ANL). About $20 \times 20 \times 7 \mu^{3}$ polycrystalline akimotoite aggregates were loaded into the sample chambers. For XRD measurements, Au powder was spread on top of akimotoite samples to serve as pressure standard with minimal pressure gradient between samples and $\mathrm{Au}^{36}$. During XES and SMS measurements, pressures were determined from the edge of the diamond Raman peak recorded from the tip of the diamond anvil at the sample position before and after each data collection ${ }^{66}$. For XRD experiments, the COMPRES/GSECARS gas- 
loading system at APS, ANL was used to load neon into the sample chamber as a hydrostatic pressure medium. For XES and SMS measurements, the pressure medium was silicone oil.

XRD. Angle-dispersive XRD measurements were performed at beamline 13-BM-C of the APS, ANL. The incident X-ray beam had a monochromatic wavelength of $0.434 \AA$ and was focused to a spot size with a full width at half maximum of $15 \times 15 \mu \mathrm{m}^{2}$. Diffracted X-rays were recorded on a MAR165 CCD detector. The sample-to-detector distance and the tilt angle and rotation angle of the image plate relative to the incident X-ray beam were calibrated by 1 bar diffraction of $\mathrm{LaB}_{6}$. At intervals of 1-2 GPa, XRD images of the samples were recorded for an exposure time of $60 \mathrm{~s}$. The XRD images were integrated using the software DIOPTAS. Diffraction patterns were analyzed using the software FullProf to examine the crystal structure and extract lattice parameters.

The compression curve of our Bdg sample exhibits softening between 43.1 and $52.5 \mathrm{GPa}$. In this pressure range a discontinuity is also observed in the corresponding normalized stress $F=\mathrm{P} / 3 f(1+2 f)^{5 / 2}$ vs. Eulerian strain $f=\left[\left(V / V_{0}\right)^{-2 / 3}-1\right] / 2$ plot (Fig. 2). The horizontal segments below and above 43.1-52.5 GPa in F-f plot demonstrate that second order Birch-Murnaghan EoS is sufficient to fit the compression data (Fig. 2). The fraction of the HS state $\left(n_{\mathrm{LS}}\right)$ in the softening segment of the compression curve is determined by the method introduced by ref. ${ }^{32}: V=\left(1-n_{\mathrm{LS}}\right) V_{\mathrm{HS}}+n_{\mathrm{LS}} V_{\mathrm{LS}}$, and the corresponding bulk modulus $(K)$ of the mixed spin state is calculated by the following equation:

$$
\frac{V}{K}=\left(1-n_{\mathrm{LS}}\right) \frac{V_{\mathrm{HS}}}{K_{\mathrm{HS}}}+n_{\mathrm{LS}} \frac{V_{\mathrm{LS}}}{K_{\mathrm{LS}}}-\left(V_{\mathrm{LS}}-V_{\mathrm{HS}}\right)\left(\frac{\partial n_{\mathrm{LS}}}{\partial P}\right)_{T},
$$

where $V_{\mathrm{HS}}$ and $V_{\mathrm{LS}}$ are the unit cell volume of HS and LS states at a given pressure $P$, respectively. The fitted HS fraction $n_{\mathrm{HS}}=1-n_{\mathrm{LS}}$ is shown in Fig. $3 \mathrm{~b}$ and the calculated bulk modulus $(K)$ and bulk sound velocity $\left(V_{\mathrm{B}}\right)$ are plotted against pressure in Supplementary Fig. 7.

XES. XES measurements were performed at beamline 16-ID-D of the APS and ANL at pressures up to $84.9 \mathrm{GPa}$ at $300 \mathrm{~K}$ (Fig. 3). The incident X-ray beam with $5 \times 7 \mu \mathrm{m}^{2}$ full width at half maximum was focused on the sample. Fluorescence signal was observed through the Be gasket. The incident $\mathrm{X}$-ray energy was $11.3 \mathrm{keV}$ with a bandwidth of $\sim 1 \mathrm{eV}$. Fe $\mathrm{K}_{\beta}$ emission was selected by silicon analyzer and reflected to a silicon detector with an energy step of about $0.3 \mathrm{eV}^{67}$. Each spectrum took about $40 \mathrm{~min}$ and 1-3 spectra were taken to accumulate at least 30,000 counts at the Fe $K_{\beta}$ main peak at each pressure.

Each spectrum is composed of an Fe $K_{\beta}$ main peak and a well-resolved lower energy satellite $K_{\beta^{\prime}}$ peak. Both integrated absolute difference (IAD) and integrated relative difference (IRD) methods ${ }^{68}$ were used to quantitatively analyze the total spin moment. Spectra were first normalized to area and aligned to the position of the Fe $K_{\beta}$ main peak (Fig. 3a). Intensity difference between the sample and standards was integrated over the whole energy range (7018.3-7083.8 eV) for IAD, but only around the satellite $K_{\beta^{\prime}}$ peak $(7018.3-7054.0 \mathrm{eV})$ for IRD. Both the spectra of $\mathrm{Fe}_{2} \mathrm{O}_{3}$ and the sample at 1 bar served as $\mathrm{HS}$ references and $\mathrm{FeS}_{2}$ at 1 bar was used as the LS reference. The spectra of references were collected using the same setup to prevent systematic error. The use of different HS standards generates $<5 \%$ difference, which provides an estimate of uncertainty (Fig. 3b). The pressure range of the spin transition observed in XES is broader than that derived from softening of the compression curve (perhaps due to use of a less hydrostatic pressure medium in this experiment), but centered at the same average transition pressure of 48-49 GPa (Fig. 3b).

Nuclear forward scattering. Time-domain SMS measurements were performed at $26-71 \mathrm{GPa}$ and $300 \mathrm{~K}$ at beamline 3ID-B of the APS. The storage ring was operated in hybrid mode, offering a $\sim 50 \%$ longer time window than the typical 24-bunch mode for data collection and thus stronger constraints on the hyperfine parameters. The X-ray beam was focused to $\sim 20 \times 20 \mu \mathrm{m}$. Spectra were typically collected for $12 \mathrm{~h}$. All SMS spectra were fitted using the CONUSS package using a two-site model with fixed equal intensity weighting based on the chemical formula (Supplementary Fig. 2). The small QS values of both sites relative to $\mathrm{HS} \mathrm{Fe}^{2+}$ and small difference in $\mathrm{CS}\left(\Delta \mathrm{CS}<0.3 \mathrm{~mm} \mathrm{~s}^{-1}\right)$ between these two sites demonstrate that all Fe in our Bdg sample is $\mathrm{Fe}^{3+69}$. Because QS and CS values for Fe generally increase with increasing coordination ${ }^{69}$, the site with smaller CS is assigned to the sixfold-coordinated B-site and the site with larger $\mathrm{CS}$ is assigned to the 8-12-fold-coordinated A-site. Across the spin transition at 43-53 GPa, QS of the A-site $\mathrm{Fe}^{3+}$ increases by $0.1-0.2 \mathrm{~mm} \mathrm{~s}^{-1}$, while that of the $\mathrm{B}$-site $\mathrm{Fe}^{3+}$ increases by $0.2-0.3 \mathrm{~mm} \mathrm{~s}^{-1}$ (Supplementary Fig. 2). This moderate increase in QS across the spin transition of $\mathrm{Fe}^{3+}$ is consistent with previous experimental studies on bridgmanite ${ }^{34,35}$ (Supplementary Fig. 3). In comparison, only the lower bound of theoretically predicted QS of B-site LS Fe ${ }^{3+}$ is marginally consistent with our results (Supplementary Fig. 3). Because QS of different sites and valence states can be similar, interpreting time-domain SMS data for Bdg requires long-time-window spectra for unique fits, clear evidence of spin transition in complementary XRD and XES results, and well-defined Bdg samples without alteration in compositions and oxidation state during high-pressure experiments.
Electrical resistance measurements. In situ high-pressure electric resistance was measured by a four-point-probe system at High Pressure Synergetic Consortium (HPSynC) at the APS. The resistance measurement system is composed of a Keithley 6221 current source, a 2182 A nanovoltmeter, and a 7001 voltage/current switch system. $\mathrm{Mg}_{0.46} \mathrm{Fe}_{1.04} \mathrm{Si}_{0.49} \mathrm{O}_{3}$ akimotoite sample was loaded into a symmetric DAC with $300-\mu \mathrm{m}$ diamonds. A stainless steel gasket was first preindented to 15 GPa with $50 \mu \mathrm{m}$ in thickness, then the indent was milled out and replaced by cubic boron nitride $(\mathrm{cBN})$. Four $10-\mu \mathrm{m}$ Au leads were pressed into contact with the sample and insulated from the stainless steel gasket by cBN powder (Supplementary Fig. 6). Current was supplied through two adjacent Au leads while the other two leads measured the corresponding voltage (marked in Supplementary Fig. 6). The first set of resistance measurements was collected during compression, then the pressure was released and the DAC was compressed again for the second set of resistance measurements (Fig. 5). The electrical conductivity was calculated by using the measured resistance, the distances between leads and established sample thickness before compression and after decompression. Due to its incompressibility, the thickness of $\mathrm{cBN}$ insert only changed by $<10 \%$ between 20 $\mathrm{GPa}$ and up to $60 \mathrm{GPa}$, as observed in a test experiment. As a result, the uncertainty of calculated electrical conductivity caused by the sample dimension is likely to be $<10 \%$, which is supported by the reproducibility of the electrical conductivity derived from two successive runs in the same DAC (Fig. 5 and Supplementary Table 4).

Data availability. The datasets generated during and/or analyzed during the current study are available as Supplementary Information and from the corresponding authors.

Received: 23 July 2017 Accepted: 5 March 2018

Published online: 29 March 2018

\section{References}

1. Frost, D. J. \& McCammon, C. A. The redox state of Earth's mantle. Annu. Rev. Earth Planet. Sci. 36, 389-420 (2008).

2. Torsvik, T. H., Burke, K., Steinberger, B., Webb, S. J. \& Ashwal, L. D. Diamonds sampled by plumes from the core-mantle boundary. Nature 466, 352-355 (2010).

3. Cottrell, E. \& Kelley, K. A. Redox heterogeneity in mid-ocean ridge basalts as a function of mantle source. Science 340, 1314-1317 (2013).

4. Walter, M. J. et al. Deep mantle cycling of oceanic crust: evidence from diamonds and their mineral inclusions. Science 334, 54-57 (2011).

5. Smith, E. M. et al. Large gem diamonds from metallic liquid in Earth's deep mantle. Science 354, 1403-1405 (2016).

6. Houser, C., Masters, G., Shearer, P. \& Laske, G. Shear and compressional velocity models of the mantle from cluster analysis of long-period waveforms. Geophys. J. Int. 174, 195-212 (2008).

7. Simmons, N. A., Forte, A. M., Boschi, L. \& Grand, S. P. GyPSuM: a joint tomographic model of mantle density and seismic wave speeds. J. Geophys. Res.-Solid Earth 115, B12310 (2010).

8. Koelemeijer, P., Deuss, A. \& Ritsema, J. Density structure of Earth's lowermost mantle from Stoneley mode splitting observations. Nat. Commun. 8, 15241 (2017).

9. Mitrovica, J. X. \& Forte, A. M. A new inference of mantle viscosity based upon joint inversion of convection and glacial isostatic adjustment data. Earth Planet. Sci. Lett. 225, 177-189 (2004).

10. Rudolph, M. L., Lekic, V. \& Lithgow-Bertelloni, C. Viscosity jump in Earth's mid-mantle. Science 350, 1349-1352 (2015).

11. Olsen, N. Induction studies with satellite data. Surv. Geophys. 20, 309-340 (1999).

12. Civet, F., Thebault, E., Verhoeven, O., Langlais, B. \& Saturnino, D. Electrical conductivity of the Earth's mantle from the first Swarm magnetic field measurements. Geophys. Res. Lett. 42, 3338-3346 (2015).

13. Ni, S., Tan, E., Gurnis, M. \& Helmberger, D. Sharp sides to the African superplume. Science 296, 1850-1852 (2002).

14. Ishii, M. \& Tromp, J. Normal-mode and free-air gravity constraints on lateral variations in velocity and density of Earth's mantle. Science 285, 1231-1236 (1999).

15. Lau, H. C. P. et al. Tidal tomography constrains Earth's deep-mantle buoyancy. Nature 551, 321 (2017)

16. Garnero, E. J., McNamara, A. K. \& Shim, S. H. Continent-sized anomalous zones with low seismic velocity at the base of Earth's mantle. Nat. Geosci. 9, 481-489 (2016).

17. Trampert, J., Deschamps, F., Resovsky, J. \& Yuen, D. Probabilistic tomography maps chemical heterogeneities throughout the lower mantle. Science 306, 853-856 (2004) 
18. Hirose, K., Sinmyo, R. \& Hernlund, J. Perovskite in Earth's deep interior. Science 358, 734-738 (2017).

19. Dorfman, S. M. \& Duffy, T. S. Effect of Fe-enrichment on seismic properties of perovskite and post-perovskite in the deep lower mantle. Geophys. J. Int. 197, 910-919 (2014).

20. Gu, T. T., Li, M. M., McCammon, C. \& Lee, K. K. M. Redox-induced lower mantle density contrast and effect on mantle structure and primitive oxygen. Nat. Geosci. 9, 723-727 (2016).

21. Catalli, K. et al. Spin state of ferric iron in $\mathrm{MgSiO}_{3}$ perovskite and its effect on elastic properties. Earth Planet. Sci. Lett. 289, 68-75 (2010).

22. Catalli, K. et al. Effects of the $\mathrm{Fe}^{3+}$ spin transition on the properties of aluminous perovskite-new insights for lower-mantle seismic heterogeneities. Earth Planet. Sci. Lett. 310, 293-302 (2011).

23. Hsu, H., Blaha, P., Cococcioni, M. \& Wentzcovitch, R. M. Spin-state crossover and hyperfine interactions of ferric iron in $\mathrm{MgSiO}_{3}$ perovskite. Phys. Rev. Lett. 106, 118501 (2011)

24. Mao, Z., Lin, J. F., Yang, J., Inoue, T. \& Prakapenka, V. B. Effects of the $\mathrm{Fe}^{3+}$ spin transition on the equation of state of bridgmanite. Geophys. Res. Lett. 42, 4335-4342 (2015).

25. Shukla, G., Cococcioni, M. \& Wentzcovitch, R. M. Thermoelasticity of $\mathrm{Fe}^{3+}$ and Al-bearing bridgmanite: Effects of iron spin crossover. Geophys. Res. Lett. 43, 5661-5670 (2016).

26. Shukla, G. \& Wentzcovitch, R. M. Spin crossover in $\left(\mathrm{Mg}, \mathrm{Fe}^{3+}\right)\left(\mathrm{Si}_{1} \mathrm{Fe}^{3+}\right) \mathrm{O}_{3}$ bridgmanite: Effects of disorder, iron concentration, and temperature. Phys Earth Planet. Inter 260, 53-61 (2016).

27. Lin, J. F., Speziale, S., Mao, Z. \& Marquardt, H. Effects of the electronic spin transitions of iron in lower mantle minerals: implications for deep mantle geophysics and geochemistry. Rev. Geophys. 51, 244-275 (2013).

28. McCammon, C. et al. Stable intermediate-spin ferrous iron in lower-mantle perovskite. Nat. Geosci. 1, 684-687 (2008).

29. Lin, J. F. et al. Intermediate-spin ferrous iron in lowermost mantle postperovskite and perovskite. Nat. Geosci. 1, 688-691 (2008).

30. Bengtson, A., Li, J. \& Morgan, D. Mössbauer modeling to interpret the spin state of iron in ( $\mathrm{Mg}, \mathrm{Fe}) \mathrm{SiO}_{3}$ perovskite. Geophys. Res. Lett. 36, L15301 (2009).

31. Dziewonski, A. M. \& Anderson, D. L. Preliminary reference Earth model. Phys. Earth Planet. Inter. 25, 297-356 (1981).

32. Wentzcovitch, R. M. et al. Anomalous compressibility of ferropericlase throughout the iron spin cross-over. Proc. Natl Acad. Sci. USA 106, 8447-8452 (2009).

33. Justo, J. F., Morra, G. \& Yuen, D. A. Viscosity undulations in the lower mantle: the dynamical role of iron spin transition. Earth Planet. Sci. Lett. 421, 20-26 (2015).

34. Potapkin, V. et al. Effect of iron oxidation state on the electrical conductivity of the Earth's lower mantle. Nat. Commun. 4, 1427 (2013).

35. Sinmyo, R., McCammon, C. \& Dubrovinsky, L. The spin state of $\mathrm{Fe}^{3+}$ in lower mantle bridgmanite. Am. Mineral. 102, 1263-1269 (2017).

36. Liu, J. C., Li, J. \& Ikuta, D. Elastic softening in $\mathrm{Fe}_{7} \mathrm{C}_{3}$ with implications for Earth's deep carbon reservoirs. J. Geophys. Res. -Solid Earth 121, 1514-1524 (2016).

37. Tsuchiya, T. \& Wang, X. L. Ab initio investigation on the high-temperature thermodynamic properties of $\mathrm{Fe}^{3+}$-bearing $\mathrm{MgSiO}_{3}$ perovskite. J. Geophys. Res. -Solid Earth 118, 83-91 (2013).

38. Boffa Ballaran, T. et al. Effect of chemistry on the compressibility of silicate perovskite in the lower mantle. Earth Planet. Sci. Lett. 333, 181-190 (2012).

39. Dorfman, S. M., Meng, Y., Prakapenka, V. B. \& Duffy, T. S. Effects of Feenrichment on the equation of state and stability of $(\mathrm{Mg}, \mathrm{Fe}) \mathrm{SiO}_{3}$ perovskite. Earth Planet. Sci. Lett. 361, 249-257 (2013).

40. Fujino, K. et al. Spin transition of ferric iron in Al-bearing Mg-perovskite up to $200 \mathrm{GPa}$ and its implication for the lower mantle. Earth Planet. Sci. Lett. 317, 407-412 (2012).

41. Ismailova, L. et al. Stability of Fe,Al-bearing bridgmanite in the lower mantle and synthesis of pure Fe-bridgmanite. Sci. Adv. 2, el600427 (2016).

42. Irifune, T. et al. Iron partitioning and density changes of pyrolite in Earth's lower mantle. Science 327, 193-195 (2010).

43. Lin, J. F. et al. Electrical conductivity of the lower-mantle ferropericlase across the electronic spin transition. Geophys. Res. Lett. 34, L16305 (2007).

44. Ohta, K., Hirose, K., Onoda, S. \& Shimizu, K. The effect of iron spin transition on electrical conductivity of $(\mathrm{Mg}, \mathrm{Fe}) \mathrm{O}$ magnesiowustite. Proc. Jpn. Acad. Ser. B Phys. Biol. Sci. 83, 97-100 (2007).

45. Ohta, K., Hirose, K., Shimizu, K., Sata, N. \& Ohishi, Y. The electrical resistance measurements of $(\mathrm{Mg}, \mathrm{Fe}) \mathrm{SiO}_{3}$ perovskite at high pressures and implications for electronic spin transition of iron. Phys. Earth Planet. Inter. 180, 154-158 (2010).

46. Sinmyo, R., Pesce, G., Greenberg, E., McCammon, C. \& Dubrovinsky, L. Lower mantle electrical conductivity based on measurements of Al, Fe-bearing perovskite under lower mantle conditions. Earth Planet. Sci. Lett. 393, 165-172 (2014).
47. Kurnosov, A., Marquardt, H., Frost, D. J., Boffa Ballaran, T. \& Ziberna, L. Evidence for a $\mathrm{Fe}^{3+}$-rich pyrolitic lower mantle from $(\mathrm{Al}, \mathrm{Fe})$-bearing bridgmanite elasticity data. Nature 543, 543-546 (2017).

48. Wang, X., Tsuchiya, T. \& Hase, A. Computational support for a pyrolitic lower mantle containing ferric iron. Nat. Geosci. 8, 556-559 (2015).

49. Frost, D. J. et al. Experimental evidence for the existence of iron-rich metal in the Earth's lower mantle. Nature 428, 409-412 (2004).

50. Liu, J. C., Mysen, B., Fei, Y. W. \& Li, J. Recoil-free fractions of iron in aluminous bridgmanite from temperature-dependent Mössbauer spectra. Am. Mineral. 100, 1978-1984 (2015).

51. Shim, S. H. et al. Stability of ferrous-iron-rich bridgmanite under reducing midmantle conditions. Proc. Natl Acad. Sci. USA 114, 6468-6473 (2017).

52. Hsu, H., Yu, Y. G. G. \& Wentzcovitch, R. M. Spin crossover of iron in aluminous $\mathrm{MgSiO}_{3}$ perovskite and post-perovskite. Earth Planet. Sci. Lett. 359, 34-39 (2012).

53. Mohn, C. E. \& Trønnes, R. G. Iron spin state and site distribution in $\mathrm{FeAlO}_{3}$ bearing bridgmanite. Earth Planet. Sci. Lett. 440, 178-186 (2016).

54. Piet, H. et al. Spin and valence dependence of iron partitioning in Earth's deep mantle. Proc. Natl. Acad. Sci. USA 113, 11127-11130 (2016).

55. Lin, J. F. et al. High-spin $\mathrm{Fe}^{2+}$ and $\mathrm{Fe}^{3+}$ in single-crystal aluminous bridgmanite in the lower mantle. Geophys. Res. Lett. 43, 6952-6959 (2016).

56. Xu, W., Lithgow-Bertelloni, C., Stixrude, L. \& Ritsema, J. The effect of bulk composition and temperature on mantle seismic structure. Earth Planet. Sci. Lett. 275, 70-79 (2008)

57. Xu, S., Shim, S. H. \& Morgan, D. Origin of $\mathrm{Fe}^{3+}$ in Fe-containing, Al-free mantle silicate perovskite. Earth Planet. Sci. Lett. 409, 319-328 (2015).

58. Marquardt, H. \& Miyagi, L. Slab stagnation in the shallow lower mantle linked to an increase in mantle viscosity. Nat. Geosci. 8, 311-314 (2015).

59. Fukao, Y. \& Obayashi, M. Subducted slabs stagnant above, penetrating through, and trapped below the $660 \mathrm{~km}$ discontinuity. J. Geophys. Res. -Solid Earth 118, 5920-5938 (2013)

60. French, S. W. \& Romanowicz, B. Broad plumes rooted at the base of the Earth'smantle beneath major hotspots. Nature 525, 95-99 (2015).

61. Murakami, M., Ohishi, Y., Hirao, N. \& Hirose, K. A perovskitic lower mantle inferred from high-pressure, high-temperature sound velocity data. Nature 485, 90-94 (2012).

62. Ballmer, M. D., Houser, C., Hernlund, J. W., Wentzcovitch, R. M. \& Hirose, K. Persistence of strong silica-enriched domains in the Earth's lower mantle. Nat. Geosci. 10, 236-241 (2017).

63. Girard, J., Amulele, G., Farla, R., Mohiuddin, A. \& Karato, S. I. Shear deformation of bridgmanite and magnesiowustite aggregates at lower mantle conditions. Science 351, 144-147 (2016).

64. Bykova, E. et al. Structural complexity of simple $\mathrm{Fe}_{2} \mathrm{O}_{3}$ at high pressures and temperatures. Nat. Commun. 7, 10661 (2016).

65. Wang, Y. B., Uchida, T., Zhang, J. Z., Rivers, M. L. \& Sutton, S. R. Thermal equation of state of akimotoite $\mathrm{MgSiO}_{3}$ and effects of the akimotoite-garnet transformation on seismic structure near the $660 \mathrm{~km}$ discontinuity. Phys. Earth Planet. Inter. 143, 57-80 (2004).

66. Akahama, Y. \& Kawamura, H. Pressure calibration of diamond anvil Raman gauge to $410 \mathrm{GPa}$. J. Phys. 215, 1-5 (2010).

67. Xiao, Y. M. New developments in high pressure X-ray spectroscopy beamline at High Pressure Collaborative Access Team. Rev. Sci. Instrum. 86, 072206 (2015).

68. Mao, Z. et al. Spin and valence states of iron in Al-bearing silicate glass at high pressures studied by synchrotron Mössbauer and X-ray emission spectroscopy. Am. Mineral. 99, 415-423 (2014).

69. Dyar, M. D., Agresti, D. G., Schaefer, M. W., Grant, C. A. \& Sklute, E. C. Mössbauer spectroscopy of Earth and planetary materials. Annu. Rev. Earth Planet. Sci. 34, 83-125 (2006).

70. Nishio-Hamane, D., Seto, Y., Fujino, K. \& Nagai, T. Effect of FeAlO incorporation into $\mathrm{MgSiO}_{3}$ on the bulk modulus of perovskite. Phys. Earth Planet. Inter. 166, 219-225 (2008)

\section{Acknowledgements}

The authors thank Jung-Fu Lin, Renata Wentzcovitch, Allen McNamara, Jeroen Ritsema Zhixue Du, Wenzhong Wang, Shuai Zhang, and Xiang Wu for helpful discussion. This work was supported by new faculty startup funding to S. M. Dorfman from Michigan State University and National Science Foundation EAR-1664332. Jie Li acknowledges support from NASA NNX15AG54G and NSF AST 1344133. Portions of the experiments were performed at GSECARS (sector 13), HPCAT (sector 16) and sector 3, Advanced Photon Source (APS), Argonne National Laboratory. GeoSoilEnviroCARS is supported by the National Science Foundation-Earth Sciences (EAR-1634415) and Department of Energy-GeoSciences (DE-FG02-94ER14466). Use of the COMPRES-GSECARS gasloading system and the PX2 program were supported by COMPRES under NSF Cooperative Agreement EAR-1606856 and by GSECARS through NSF grant EAR1634415 and DOE grant DE-FG02-94ER14466. HPCAT operations are supported by DOE-NNSA under Award No. DE-NA0001974, with partial instrumentation funding by NSF. Y.X. acknowledges the support of DOE-BES/DMSE under Award DE-FG02- 
99ER45775. The Advanced Photon Source is a U.S. Department of Energy (DOE) Office of Science User Facility operated for the DOE Office of Science by Argonne National Laboratory under Contract No. DE-AC02-06CH11357.

\section{Author contributions}

J.L. and S.M.D. designed research; J.L., S.M.D., F.Z., J.L., Y.W., D.Z., Y.X., W.B., and E.E. A performed research. J.L. and S.M.D. analyzed data; J.L. and S.M.D. wrote the paper.

\section{Additional information}

Supplementary Information accompanies this paper at https://doi.org/10.1038/s41467018-03671-5.

Competing interests: The authors declare no competing interests.

Reprints and permission information is available online at http://npg.nature.com/ reprintsandpermissions/

Publisher's note: Springer Nature remains neutral with regard to jurisdictional claims in published maps and institutional affiliations. (c) (i) Open Access This article is licensed under a Creative Commons Attribution 4.0 International License, which permits use, sharing, adaptation, distribution and reproduction in any medium or format, as long as you give appropriate credit to the original author(s) and the source, provide a link to the Creative Commons license, and indicate if changes were made. The images or other third party material in this article are included in the article's Creative Commons license, unless indicated otherwise in a credit line to the material. If material is not included in the article's Creative Commons license and your intended use is not permitted by statutory regulation or exceeds the permitted use, you will need to obtain permission directly from the copyright holder. To view a copy of this license, visit http://creativecommons.org/ licenses/by/4.0/.

(C) The Author(s) 2018 